\title{
The effect of acoustical treatment on primary school children's performance, sound perception, and influence assessment
}

\author{
Dadi Zhang ${ }^{1,}{ }^{*}$, Martin Tenpierik ${ }^{1}$, Philomena M. Bluyssen ${ }^{1}$ \\ ${ }^{1}$ Faculty of Architecture and the Built environment, Delft University of Technology, Delft, The Netherlands
}

\begin{abstract}
A previous field study showed that more than $85 \%$ of Dutch children reported they were bothered by noise in the classroom. To investigate the impact of acoustical treatment on children's phoneme identification, 335 school children (9 to 13 years old) from the previously studied schools were invited to take part in a series of tests in the acoustical chamber of the SenseLab. All the children performed two series of listening tests and evaluations in chamber A (untreated) and chamber B (acoustically treated) respectively, while at the same time one of seven background sounds $(45 \mathrm{~dB}$ or $60 \mathrm{~dB}$ traffic noise, $45 \mathrm{~dB}$ or $60 \mathrm{~dB}$ children talking, $45 \mathrm{~dB}$ or $60 \mathrm{~dB}$ music, or no sound) were randomly played in the chambers. T-tests were conducted to compare the results of children's phonological process tasks, sound perceptions, and influence assessments in these two chambers. Results showed a statistically significant difference in children's sound perceptions ( $\mathrm{p}=0.01$ ). Children reported the untreated chamber A to be noisier.
\end{abstract}

\section{Introduction}

Over the past decades, the acoustical condition of classrooms has arisen much attention because of its important role in school children's comfort and performance. Several previous studies indicated that children are much more impaired than adults by noise and exposure to noise may impair children's performance [1]. Results of a previous field study conducted by Bluyssen et al. [2] showed that noise was the main annoyance for children in classrooms in the Netherlands. $98 \%$ of children could hear noise in their classroom and $87 \%$ of children reported to be bothered by the noise. Such an unfavourable learning environment might have a negative impact on children's comfort, performance and health $[3,4]$. Therefore, improvement of the acoustics in classrooms is an important topic to consider for research.

Reverberation time (RT), as one of the major parameters to measure the acoustics, is often used in guidelines, such as the Requirement of Fresh Schools in the Netherlands and the Building Bullentin 93 in the UK. Many studies have found that a longer RT could impair children's performance [3] [5], especially for children who have a hearing problem [6] and who are not native speakers [7].

Several ways to improve the RT in classrooms have been studied before, for example using acoustical ceiling tiles [8] or fleecy floor coverings (carpets) [9]. All of them have been proved to be effective to reduce the potential noise perception in a classroom. However, only few studies investigated children's response to these or other forms of acoustical treatment.
Therefore, to examine the effect of acoustical treatment of a room on children, this study was carried out. 335 primary school children were invited to participate in two series of experiments in the acoustical chamber of the SenseLab, which was divided into an acoustically treated and an untreated part [10]. In these two chambers, children were asked to perform two series of tasks and evaluations, while one of seven background sounds $(45 \mathrm{~dB}(\mathrm{~A})$ or $60 \mathrm{~dB}(\mathrm{~A})$ children talk, $45 \mathrm{~dB}(\mathrm{~A})$ or $60 \mathrm{~dB}(\mathrm{~A})$ traffic, $45 \mathrm{~dB}(\mathrm{~A})$ or $60 \mathrm{~dB}(\mathrm{~A})$ music, or no sound $(\approx 30 \mathrm{~dB}(\mathrm{~A})))$ was randomly playing. This current paper shows the result of the comparison of children 's performance, sound perceptions, and the influence assessment between these two chambers. The effect of sound type and sound pressure level on children will be reported elsewhere.

\section{Methodology}

\subsection{Study design}

This study was part of a series of tests performed in the SenseLab [9], with 335 children from seven primary schools that took place on 10 different days between February 13 and April 5, 2018 [10].

\subsection{Facilities}

The study reported here was conducted in the acoustical chamber of the SenseLab (width $2.4 \mathrm{~m}$, length $2.6 \mathrm{~m}$, height $2.1 \mathrm{~m})$. The chamber was equally divided into two parts (or two chambers) by a thick curtain. One of them did not have any acoustical treatment, so it was called

\footnotetext{
* Corresponding author: d.zhang-2@rtudelft.nl
} 
the untreated chamber A, while in the other one acoustical absorption panels were attached to the three walls and ceiling by magnets, and was named the acoustically treated chamber B. The estimated RTs of these two chambers were 0.33 and 0.07 seconds, respectively (average from 250 to $2000 \mathrm{~Hz}$ ). In each chamber, there was a speaker placed in a corner and two chairs placed on the opposite side (see Fig. 1). Both of the speakers in these chambers were controlled through a laptop and played the same sound files at the same time.
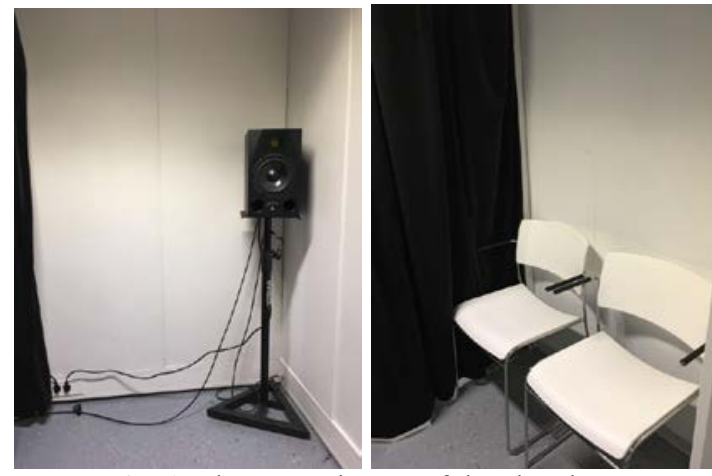

Fig. 1. The set-up in one of the chambers.

\subsection{Performance task}

To test performance, a phonological processing task, aimed to evaluate children's hearing ability, was used. In each of the questions, three consonant-vowel-consonant Dutch words, including two with similar pronunciation and one with different pronunciation (e.g. cop, cup, fos), were played together with the background sounds via the speakers. Children were asked to select the (odd) one with the different pronunciation and to mark the corresponding answer on the questionnaire (see Fig. 2). Before the test, all the words were spoken by a 38 years old Dutch male and recorded by a sound analyser (type Norsonic Nor 140), were merged with seven different background sounds respectively, using Adobe Audition software, and were calibrated in the chamber to get the correct sound pressure levels.

\subsection{Procedure}

On the day of the study, all the children first filled in a one-page personal information questionnaire, and then were divided into groups with maximum 16 children. On each experimental day, two or three groups participated. During the series of tests in the test chambers, the participating group was further divided into four subgroups and started each in one of the four test chambers of the SenseLab (the thermal, air, light and acoustics test chamber). After 7-8 minutes, the groups moved on to the next test chamber, until they had visited all of the test chambers. Before the children entered the acoustics chamber, an instructor carefully explained the procedure of the acoustic test to them, and demonstrated how to answer the questions with an example task, and then handed them a one-page questionnaire (see Fig. 2).

The acoustic test consisted of two parts, of which each comprised of four phonological processing questions, one sound proception evaluation with a fivepoint scale and one influence assessment with a threepoint scale (see Fig. 2). Children in both parts of the chamber (A and B), started the test at the same time. After the first part, they changed positions to the other part of the chamber and repeated the test. Each had a duration of three minutes. After the second time, children were asked to answer one more question: "Which chamber do you like better? And why?"

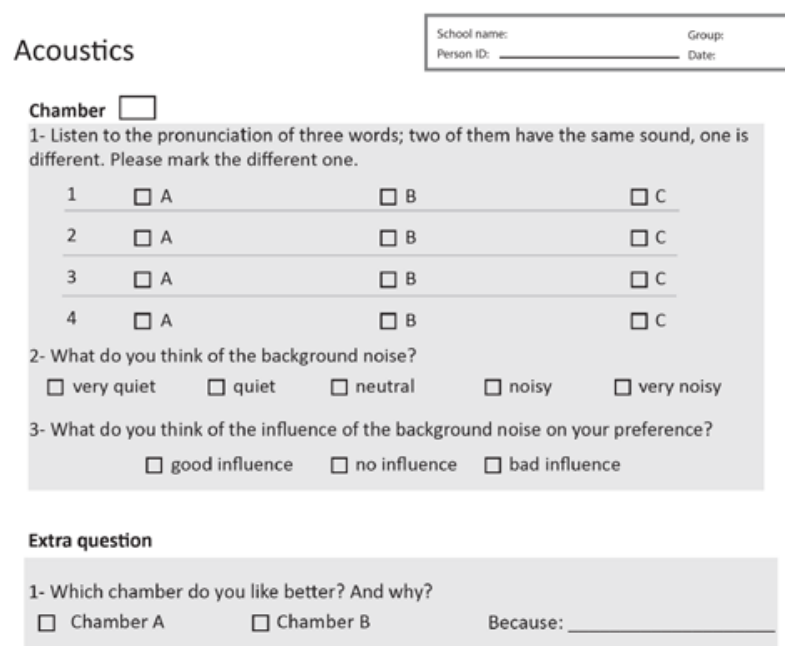

Fig. 2. Excerpt from acoustical chamber questionnaire for the listening task.

\subsection{Data management and analysis}

All the data were manually typed in and stored in IBM SPSS Statistics 24.0. For the performance tasks, one point was given for each correct answer. The total scores of each child for both tests (in Chamber A and B) were calculated. For the sound perception, the five-point scale (very noisy-noisy-neutral-quiet-very quiet) was coded into a score from 1 to 5 correspondingly. Similarly, for the influence assessment, the three-point scale (bad influence-no influence-good influence) was coded into a score from 1 to 3 .

Descriptive analysis was used to show children's personal information (e.g. age, gender etc.), and the general result of children's performance tasks, sound perceptions, and their influence assessments. In all of the analyses, except for their personal information, every child was regarded as two subjects, each one corresponding to one part of the test.

In addition, comparative analysis was also conducted to evaluate the effect of the acoustical treatment, by means of the independent-samples t-test. Results of children's performance tasks, sound perceptions, and their influence assessments were all compared between these two chambers A and B.

\subsection{Ethical aspects}

The parents of the children that participated, received and signed a consent form before the experimental day. All the forms were collected on the experimental day. Only the children whose parents agreed on their 
participation took part in the series of tests. The ethics committee of the TU Delft gave approval for the study.

\section{Results}

\subsection{Participants}

In all, 335 children including 167 girls and 168 boys participated. Among them, 14 children reported having hearing problems, 27 children of the first day used the wrong version of the questionnaire, and four children of the sixth day skipped one part because of speaker failure. All of them were excluded from the analysis. After the filtering, 290 children, including 145 girls and 145 boys, with an average age of 10.6 years (SD of 1.1 years), were left.

\subsection{Descriptives}

\subsubsection{Performance test}

According to the result of the t-tests, there was no statistically significant difference of children's test scores between Chambers A and $B(p=0.29)$. The mean value was 3.0 in chamber $A$ and 2.9 in chamber $B$ (see Table 1). As shown in Fig. 3, the percentage of children who got the full score were higher in the chamber A than in chamber B, while for the other scores, the percentage of children for those scores were almost same for the two chambers.

\subsubsection{Sound perception}

According to the result of the t-tests, there was a statistically significant difference of children's sound perceptions between the two chambers $(p<0.05)$. Children evaluated chamber A to be noisier (mean=2.7) than chamber B (mean=3.0) (see Table 1). As shown in Fig. 4, the percentages of children that selected 'very noisy' and 'noisy' were higher in chamber A than in chamber B, while for the 'neutral', 'quiet' and 'very quiet', the percentage of children was higher in chamber $B$ than in chamber A.

\subsubsection{Influence assessment}

With respect to the assessment of influence, there was no statistically significant difference of children's answers between the two chambers $(p=0.78)$. The mean value of children's influence assessment in these chambers were almost identical: 1.87 for chamber $\mathrm{A}$ and 1.89 for chamber B (see Table 1). The distributions of children's answers (Fig. 5), were also almost identical.

Table 1. Comparison of children's test scores and evaluation scores between Chamber A and B.

\begin{tabular}{ccccc}
\hline & Chamber A & Chamber B & t $^{\mathrm{a}}$ & P-values $^{\mathrm{b}}$ \\
\hline Test scores & $3.03(1.11)$ & $2.93(1.10)$ & $t_{568}=1.065$ & 0.287 \\
Sound perception & $2.70(1.07)$ & $3.01(1.15)$ & $t_{551}=-3.282$ & $\mathbf{0 . 0 0 1}$ \\
Assessment of the influence of sounds & $1.87(0.75)$ & $1.89(0.76)$ & $t_{541}=-0.278$ & 0.781
\end{tabular}

\section{Notes:}

a. The t-value obtained from t-tests, measured the size of the difference relative to the variation in the sample data. The greater the $\mathrm{t}$ value (either positive or negative), the greater the evidence that there is a significant difference.

b. P-values obtained from t-tests. P-values in bold mean statistically significant at the $5 \%$ level.

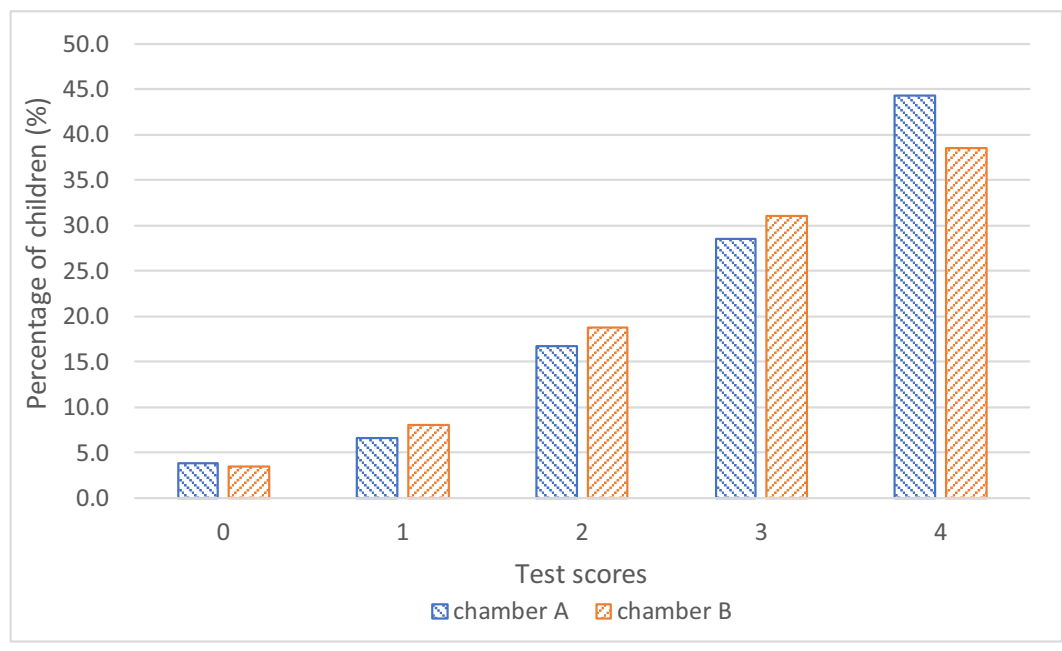

Fig. 3. The distribution of children's test scores. 


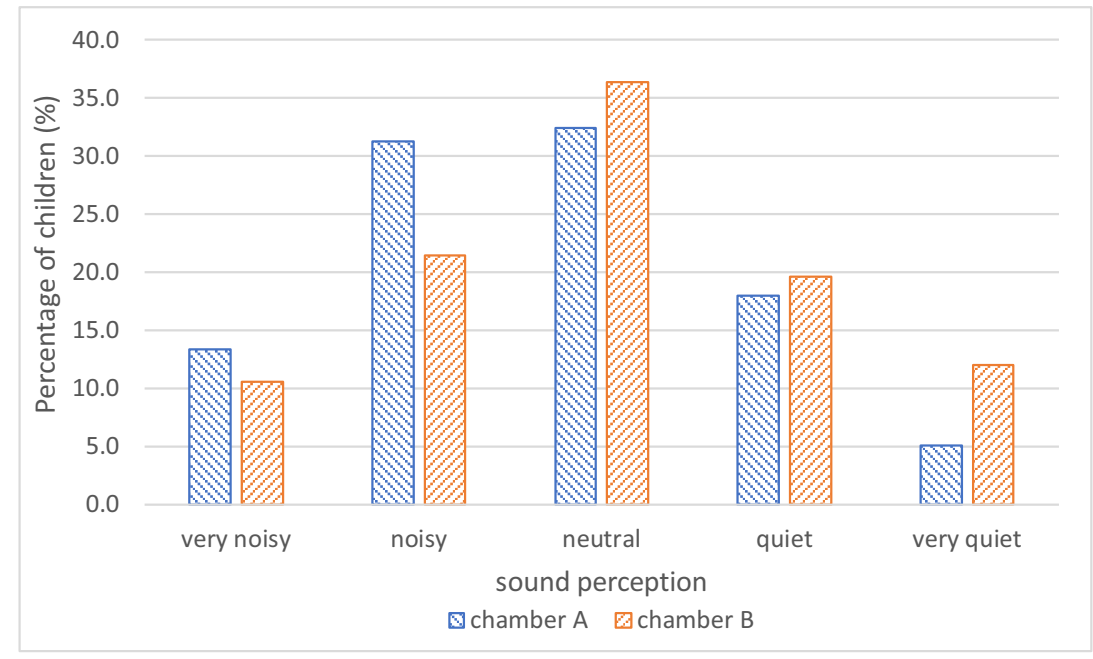

Fig. 4. The distribution of children's sound perceptions.

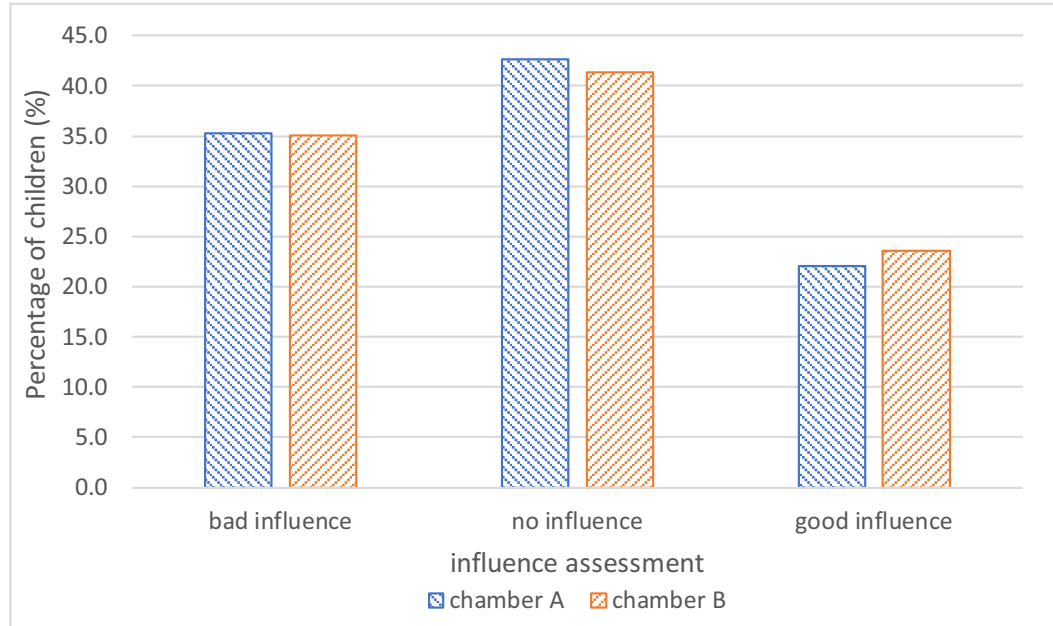

Fig. 5. The distribution of children's influence assessment

\subsection{Comparison in different background sound conditions}

To further clarify the effect of the acoustical treatment of a room on children, all the data were separated into seven files based on the seven background sounds, and then the comparison between these two chambers was conducted again in each of these conditions. The results were shown in Table 2.

\subsubsection{Performance test}

The differences of children's test scores were not significant in almost all the sound conditions, except for one: the ' $60 \mathrm{~dB}(\mathrm{~A})$ children's talk' $(\mathrm{p}=0.001)$. Under this condition, as shown in Fig. 6, children performed significantly better in chamber A (mean=3.1) than in chamber B (mean=2.5). Besides, this tendency can also be seen under the ' $45 \mathrm{~dB}(\mathrm{~A})$ children's talk' and ' 45 $\mathrm{dB}(\mathrm{A})$ traffic' sound conditions, although the differences were not significant. On the contrary, when the background sound was ' $60 \mathrm{~dB}(\mathrm{~A})$ music' or 'no sound', children performed slightly better in chamber $\mathrm{B}$.

\subsubsection{Sound perception}

Among the seven sound conditions, the statistically significant differences of children's sound perceptions between these chambers can be found in the ' $60 \mathrm{~dB}(\mathrm{~A})$ music' $(\mathrm{p}=0.035)$ and the 'no sound' $(\mathrm{p}=0.028)$ conditions. Under these two conditions, as shown in Fig.7, children evaluated chamber A to be nosier than chamber B. The same tendency can be seen in most of the other conditions, except for the ' $45 \mathrm{~dB}(\mathrm{~A})$ music'. Under this condition, children's sound perceptions were almost the same for the two chambers.

\subsubsection{Influence assessment}

With respect to the differences of children's influence assessment between these chambers, none of them was 
statistically significant under these background sound conditions. The fluctuation of children's assessment for these background sounds was quite small, the differences between the highest and the lowest assessment scores were only around 0.6 for both chambers. Children rated either no influence or bad influence for all the background sounds in both chambers.

\subsection{Children's preference of these chambers}

Table 2. Comparison between chamber A and chamber B for the different conditions

\begin{tabular}{|c|c|c|c|c|c|c|}
\hline & \multicolumn{2}{|c|}{ Test scores } & \multicolumn{2}{|c|}{ Sound perception } & \multicolumn{2}{|c|}{ Influence assessment } \\
\hline & $\mathrm{t}^{\mathrm{a}}$ & $\mathrm{P}^{\mathrm{b}}$ & $\mathrm{t}$ & $\mathrm{p}$ & $\mathrm{t}$ & $\mathrm{p}$ \\
\hline $45 \mathrm{~dB}(\mathrm{~A})$ children's talk & $t_{93}=1.563$ & 0.121 & $t_{90}=-0.872$ & 0.386 & $t_{89}=1.086$ & 0.280 \\
\hline $60 \mathrm{~dB}(\mathrm{~A})$ children's talk & $t_{60}=3.469$ & 0.001 & $t_{59}=-1.926$ & 0.059 & $t_{56}=-0.562$ & 0.576 \\
\hline $45 \mathrm{~dB}(\mathrm{~A})$ traffic & $t_{73}=1.847$ & 0.069 & $t_{70}=-1.864$ & 0.066 & $t_{69}=-1.588$ & 0.117 \\
\hline $60 \mathrm{~dB}(\mathrm{~A})$ traffic & $t_{109}=-0.420$ & 0.675 & $t_{108}=-1.977$ & 0.051 & $t_{106}=-0.793$ & 0.430 \\
\hline $45 \mathrm{~dB}(\mathrm{~A})$ music & $t_{67}=0.251$ & 0.803 & $t_{62}=0.347$ & 0.730 & $t_{62}=-0.569$ & 0.572 \\
\hline $60 \mathrm{~dB}(\mathrm{~A})$ music & $t_{90}=-1.704$ & 0.092 & $t_{91}=-2.139$ & 0.035 & $t_{90}=0.278$ & 0.781 \\
\hline No sound & $t_{62.2}=-1.038$ & 0.303 & $t_{59}=-2.253$ & 0.028 & $t_{57}=0.368$ & 0.380 \\
\hline
\end{tabular}

Notes: a. The t-value that obtained from the t-tests measured the size of the difference relative to the variation in the sample data; The greater the t-value (either positive or negative), the greater the evidence that there is a significant difference. b. P-values obtained from the t-tests; P-values in bold mean statistically significant at the $5 \%$ level.

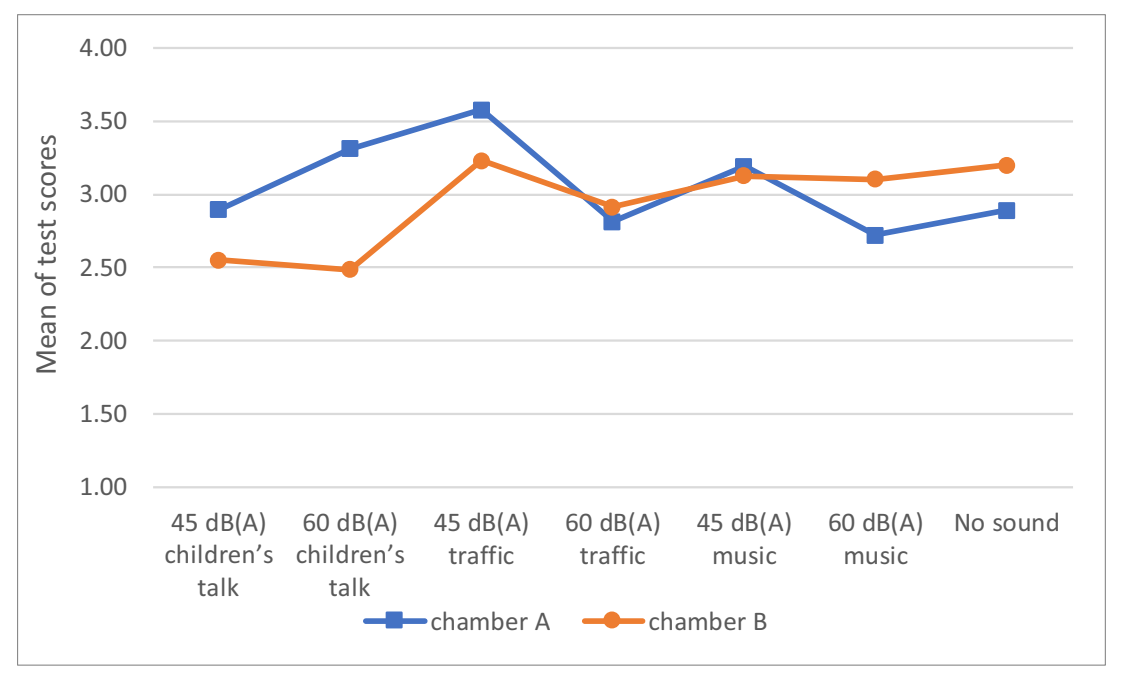

Fig. 6. Difference of children's test scores between Chamber A and B. 


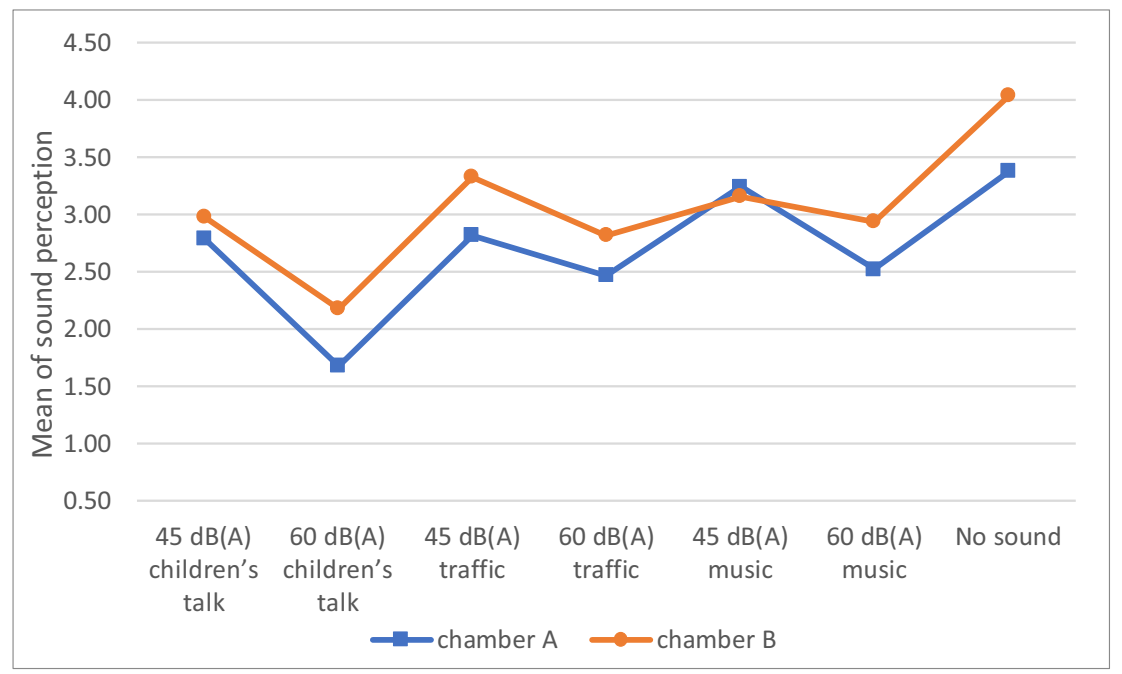

Fig. 7. Difference of children's sound perceptions between Chamber A and B.

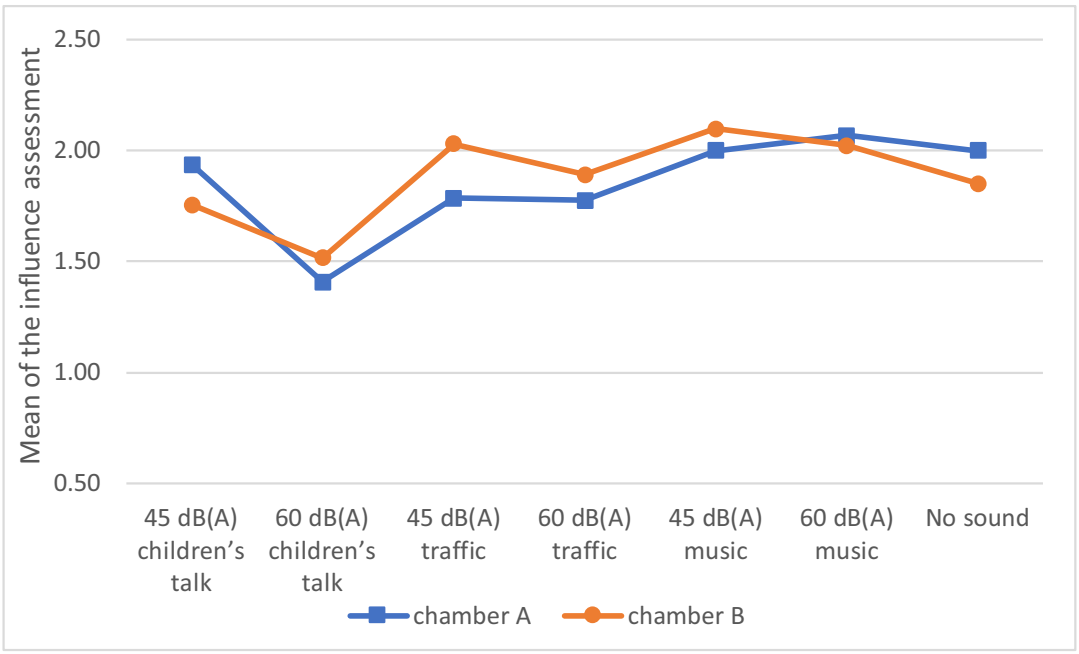

Fig. 8. Difference of children's influence assessment between Chamber A and B.

\section{Discussion}

Children's talk is the most common noise in classrooms. How to minimize its adverse effect on children's performance and comfort is one of the most important research topics. This study found that under this type of noise, children performed better in the untreated chamber $(\mathrm{RT}=0.33 \mathrm{~s})$ than the acoustically treated chamber $(\mathrm{RT}=0.07 \mathrm{~s})$. This raised the question about the RT as applied in our guidelines for classrooms. It seems that a lower RT is not always better. At this point, Nijs and Rychtáriková [11] suggested that $0.3 \mathrm{~s}$ may be the appropriate RT for a quiet classroom with high signal-tonoise ratio; If the RT is too low then overdamping may occur and the loudness of the signal may get too low, then the speech intelligibility might be high but the audibility low. Therefore, the reason why children, in general, performed worse in the treated chamber under noisy conditions might be because of this overdamping and the corresponding low audibility. They performed better in the treated under the 'music' or 'no sound' conditions might be because of the high speech intelligibility. In other words, if there is no noise in the treated chamber, the high speech intelligibility could compensate for the low audibility, while under noisy conditions, an appropriate RT is much more important. Both the speech intelligibility and the audibility should be kept at its optimum value.

Nevertheless, although the acoustical treatment was not always beneficial to children's performance, it seemed to work well for children's sound perceptions, no matter which type of background sounds. The results attained from this study indicate that the acoustical treatment does have the potential to reduce noise perception, and this is also confirmed by earlier findings on the impact of acoustical covering on noise perception [9].

In addition, this study found that from children's point of view all the background sounds, no matter whether it was noise or music and no matter with or without acoustical treatment, might have an adverse 
effect on their performance. This verified the conclusion of Shield and Dockrell [12] that noise has a detrimental effect on children's performance, and the conclusion of Hagreaves and Noth [13] that listening to music might impair children's performance since it occupies their cognitive capacity (e.g. identify the instrument, the musical components), and this impact will be more obvious when listening to high arousing music.

\section{Conclusions}

The current study was part of a series of tests performed in the SenseLab [10]. It investigated the effect of acoustical treatment of a room on children's phonological processing performance, sound perception and influence assessment by conducting a series of tests in a laboratory environment.

A statistically significant difference of children's sound perceptions between the acoustically treated chamber and the untreated chamber was found, which demonstrated the positive effect of the acoustic treatment. However, the treatment is not the more the better. It should be done moderately since over-treatment could have adverse effects on children's performance, especially with the 'children's talk' as the background sound.

Based on children's preference of these two chambers, one more conclusion might be attained: as long as there is a background sound, the acoustically treated environment was more welcomed by the children.

\section{References}

[1] E. M. Elliott, "The irrelevant-speech effect and children: Theoretical implications of developmental change," Memory \& Cognition, vol. 30, pp. 478-487, 2002.

[2] P. M. Bluyssen, D. Zhang, S. Kurvers, M. Overtoom, and M. Ortiz-Sanchez, "Selfreported health and comfort of school children in 54 classrooms of 21 Dutch school buildings," Building and Environment, vol. 138, pp. 106123, 2018.

[3] M. Klatte, J. Hellbrück, J. Seidel, and P. Leistner, "Effects of classroom acoustics on performance and well-being in elementary school children: A field study," Environment and Behavior, vol. 42, pp. 659-692, 2010.

[4] T. Catalina and T. Banu, "Impact of indoor environmental conditions on students intellectual performance," Buletinul Institutului Politehnic din lasi. Sectia Constructii, Arhitectura, vol. 60, p. 23, 2014.

[5] C. L. Rogers, J. J. Lister, D. M. Febo, J. M. Besing, and H. B. Abrams, "Effects of bilingualism, noise, and reverberation on speech perception by listeners with normal hearing," Applied Psycholinguistics, vol. 27, pp. 465-485, 2006.

[6] R. Plomp and A. Duquesnoy, "Room acoustics for the hearing impaired," The Journal of the
Acoustical Society of America, vol. 71, pp. S19S19, 1982.

[7] P. Nelson, K. Kohnert, S. Sabur, and D. Shaw, "Classroom noise and children learning through a second language: Double jeopardy?," Language, Speech, and Hearing Services in Schools, vol. 36, pp. 219-229, 2005.

[8] L. E. Maxwell, "A safe and welcoming school: What students, teachers, and parents think," Journal of Architectural and Planning Research, pp. 271-282, 2000.

[9] C. K. Tanner and A. Langford, "The Importance of Interior Design Elements as They Relate to Student Outcomes," 2003

[10] P. M. Bluyssen, F. van Zeist, S. Kurvers, M. Tenpierik, S. Pont, B. Wolters, et al., "The creation of SenseLab: a laboratory for testing and experiencing single and combinations of indoor environmental conditions," Intelligent Buildings International, pp. 1-14, 2017.

[11] L. Nijs and M. Rychtáriková, "Calculating the optimum reverberation time and absorption coefficient for good speech intelligibility in classroom design using U50," Acta Acustica united with Acustica, vol. 97, pp. 93-102, 2011.

[12] B. M. Shield and J. E. Dockrell, "The Effects of classroom and environmental noise on children's academic performance," in 9th International Congress on Noise as a Public Health Problem (ICBEN), Foxwoods, CT, 2008.

[13] A. C. North and D. J. Hargreaves, "Music and consumer behaviour," Oxford handbook of music psychology, pp. 481-490, 2009. 